\title{
Spontaneous hepatitis $C$ viral clearance and hepatitis $C$ chronic infection are associated with distinct cytokine profiles in Mexican patients
}

\author{
Nora A Fierro ${ }^{1,2}$, Karina González-Aldaco ${ }^{3,4}$, Rafael Torres-Valadez ${ }^{3,4}$, Maria E Trujillo-Trujillo ${ }^{3,4}$, \\ Sonia Roman ${ }^{3,4}$, Jorge L Trujillo-Ochoa ${ }^{1,2}$, Arturo Panduro ${ }^{3,5 /+}$ \\ 'Unidad de Inmunovirología ${ }^{3}$ Servicio de Biología Molecular en Medicina, Hospital Civil de Guadalajara Fray Antonio Alcalde, \\ Guadalajara, Jalisco, México ${ }^{2}$ Departamento de Fisiologia ${ }^{4}$ Departamento de Biología Molecular ${ }^{5}$ Departamento de Clínicas Médicas, \\ Centro Universitario de Ciencias de la Salud, Universidad de Guadalajara, Guadalajara, Jalisco, México
}

The mechanisms related to the spontaneous clearance of hepatitis $C$ virus (HCV) have been primarily studied in regions where the infection is endemic. Results of prior studies have been extrapolated to populations with low endemicity, such as Mexico. Herein, we determined the cytokine profiles in serum samples from Mexican patients who spontaneously cleared HCV and patients chronically infected with HCV genotype 1a. Chronic HCV-infected patients displayed increased interleukin (IL)-8 and regulated upon activation, normal T-cell expressed and secreted (CCL-5) secretion, whereas patients who spontaneously cleared HCV showed augmented levels of IL-1 alpha, tumour necrosis factor-alpha, transforming growth factor-beta, monocyte chemoattractant protein-2 (CCL-8), IL-13 and IL-15. Our study suggests that cytokine profiles may predict disease outcome during HCV infection.

Key words: hepatitis C virus - cytokines - viral clearance - genotype 1a

Hepatitis $\mathrm{C}$ virus (HCV) is an enveloped RNA virus belonging to the Flaviviridae family. Each year, HCV infects approximately three-four million individuals worldwide. It is estimated that 170 million people are chronically infected with $\mathrm{HCV}$ and at risk of developing chronic liver disease and 350,000 deaths occur each year due to HCV-related causes (Hanafiah et al. 2013). HCV is present worldwide, but its distribution pattern is not uniform. In Latin America, HCV genotype 1 is the most prevalent and the overall prevalence of $\mathrm{HCV}$ antibody is estimated to be $1.5 \%$ (Alvarado-Mora \& Pinho 2013). In Mexico, an identified region with low HCV prevalence, the most prevalent viral genotypes are $1 \mathrm{a}$ and $1 \mathrm{~b}$ followed by $2 \mathrm{a}$ and $3 \mathrm{~b}$ (Panduro et al. 2011). In recent years, chronic diseases associated with liver malfunction have gained increasing importance in the world (Fierro et al. 2014); thus, the study of causal agents of liver damage is of great significance.

$\mathrm{HCV}$ is able to establish lifelong persistent infection in most individuals by successfully evading the immune system. However, approximately $30 \%$ of patients spontaneously clear the virus (Rehermann \& Bertoletti 2015). The immunopathology associated with HCV infection has been predominantly studied in regions where infection is

doi: 10.1590/0074-02760140377

Financial support: CONACYT $(127229,188240)$

RT-V, MET-T and JLT-O were supported by PhD scholarships from the CONACYT, NAF, SR and AP are sponsorship recipients of the Red Temática de Colaboración Académica en Fisiopatología de las Enfermedades Hepáticas (SEP-Promep).

+Corresponding author: apanduro@prodigy.net.mx

Received 13 October 2014

Accepted 26 January 2015 common and the results have been extrapolated to regions of low endemicity. The exact mechanisms responsible for viral clearance and recovery in humans are unknown. In this context, efforts to determine whether biomarkers, including serum cytokines, can accurately predict the outcome of HCV infection are valuable for establishing better HCV control strategies in Latin American regions.

In the present study, 33 serum samples from patients ( $>18$ years of age) admitted to the Molecular Biology Service of the Fray Antonio Alcalde Civil Hospital of Guadalajara (AHCFAA) from 2011-2013 were retrospectively analysed. Hepatitis was defined as described in a previously published study (Escobedo-Meléndez et al. 2012). Informed consent was obtained from all patients involved in the study. The local ethical committee of the AHCFAA approved the study protocol.

Samples from patients with liver disease and under treatment with a hepatotoxic drug, patients with chronic hepatitis associated with an aetiological agent distinct to viral hepatitis, patients with autoimmune hepatitis and patients identified as overweight or obese were excluded from the study. Clinical history and demographic data were collected for all participants through a structured questionnaire, as previously reported (Escobedo-Meléndez et al. 2012). Serum alanine aminotransferase (ALT) and aspartate aminotransferase (AST) levels were measured using an enzymatic method (Human, Germany) with an automatic analyser. The abnormal cut-off values for ALT and AST enzymes were $40 \mathrm{UI} / \mathrm{mL}$ and $50 \mathrm{UI} / \mathrm{mL}$, respectively.

Clinical evaluation of HCV-infected patients Chronic HCV infection was defined as a positive anti$\mathrm{HCV}$ test (ELISA Third-Generation, AxSYM) result and the presence of serum HCV RNA for more than six months (COBAS ${ }^{\circledR}$ AmpliPrep and COBAS ${ }^{\circledR}$ TaqMan 48). Samples from patients who spontaneously cleared HCV tested positive for anti-HCV antibody in the absence of 
HCV RNA six months after the initial test, in accordance with the definition of spontaneous viral clearing (Hanafiah et al. 2013, EASL 2014). AST and ALT levels were determined by dry chemistry on a Vitros 250 analyser (Ortho Clinical Diagnostics, Johnson \& Johnson, USA). Viral genotyping was performed at the Bayesian Markov model through a conventional line probe assay (VERSANT HCV Genotype 2.0 Assay LiPA, Germany) after HCV RNA extraction (QIAamp RNA mini kit) and RNA amplification (VERSANT HCV LiPA 2.0 Amplification Kit) following the manufacturer's instructions.

Patients with positive viral RNA were stratified into four groups according to their fibrosis stage, as determined by transitional elastography using a FibroScan ${ }^{\circledR}$ instrument (Echosens, France). As validated by the manufacturer, the stage of fibrosis in patients with chronic HCV infection was defined as follows: F1, initial fibrosis, F2, moderate fibrosis, F3, advanced fibrosis, and F4, cirrhosis stage.

Analysis of serum cytokines - As reported previously, a standardised (Fierro et al. 2011) dot blot-based assay was used according to the manufacturer's instructions (Ray-Biotech, USA) to detect the relative expression levels of 23 cytokines in serum samples collected from patients. The following cytokines were analysed: pro-inflammatory cytokines [interleukin (IL)-8, tumour necrosis factor-alpha (TNF- $\alpha$ ), IL-2, IL-1 and IL-6], anti-inflammatory cytokines [tumour growth factor-beta (TGF- $\beta$ ) and IL-10], fibrogenic (IL-13), immunoregulatory cytokines [IL-5, IL-15, interferon-gamma (IFN- $\gamma$ ), IL-7 and TNF- $\beta$ ], chemokines [monocyte chemoattractant protein (MCP)-1 (CCL-2), MCP-2 (CCL-8), MCP-3 (CCL-7), monokine-induced by IFN- $\gamma$ (MIG) (CXCL-9) and regulated upon activation, normal T-cell expressed and secreted (RANTES) (CCL-5)] and growth factors [growth-regulated oncogene-alpha (GRO- $\alpha)$, GRO, IL-3, granulocyte-macrophage colony-stimulating factor (GMCSF) and granulocyte colony-stimulating factor (GCSF)] (Fierro et al. 2011). Briefly, the membranes were blocked with a blocking buffer and $1 \mathrm{~mL}$ of a 1:500 dilution of the patient serum was added. Next, the membranes were incubated at room temperature (RT) for 2 h. After the membranes were washed, $1 \mathrm{~mL}$ of primary biotin-conjugated antibodies was added to detect the 23 cytokines previously described and the membranes were incubated at RT for $2 \mathrm{~h}$. The membranes were incubated with $2 \mathrm{~mL}$ of horseradish peroxidase-conjugated streptavidin at RT for $1 \mathrm{~h}$, which was developed using an enhanced chemiluminescence-type solution subsequently exposed to film and processed by autoradiography. The densitometry analysis was performed with an Alpha-Innotech FluorChem Imaging System. For each membrane, the individual background value obtained from the densitometry values for the blank controls included in each assay (A in Figure) were subtracted from the densitometry values corresponding to each cytokine. The densitometry units corresponding to the relative expression levels of each cytokine are shown.

Ethics - Blood from patients and controls was obtained by venipuncture with approval from the local ethical committee of the HCFAA (IRB: HCG/CI-883/09).
The protocol was conducted in accordance with the Helsinki Declaration of 1975, as revised in 1983.

Statistical analysis - The data are reported as individual densitometry analyses for each patient for each cytokine. The mean \pm standard deviation (SD) for study groups is indicated. The data are presented as the mean \pm SD. Statistical comparisons were performed using GraphPad Prism v.5.01. A nonparametric Mann-Whitney
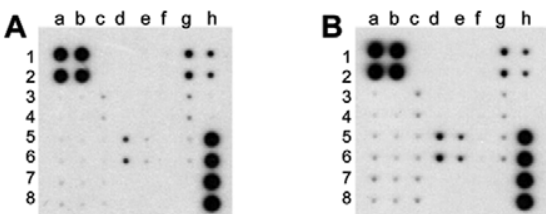

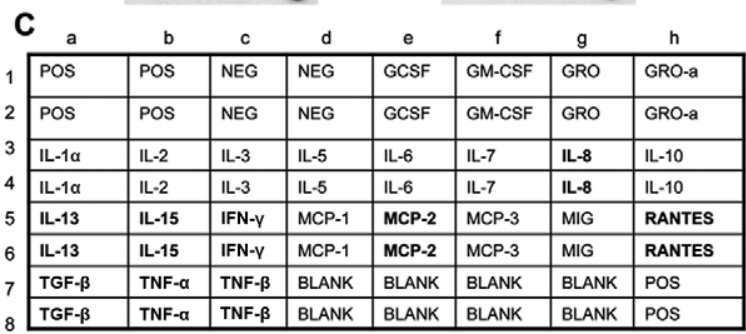
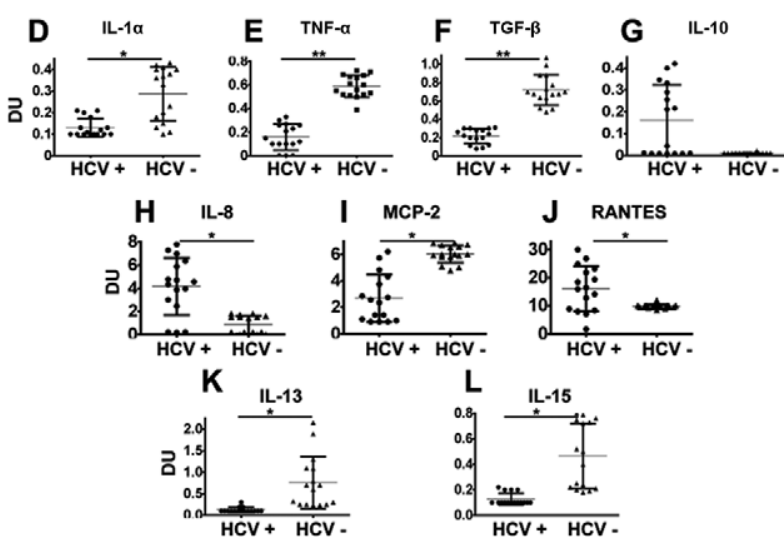

The cytokine profiles during hepatitis $\mathrm{C}$ virus (HCV) infection distinguish viral clearance from persistent infection. Representative dot blots of the study groups are shown (A: chronically HCV-infected patients with detectable viral RNA titres; B: patients who spontaneously cleared $\mathrm{HCV}$; C: an array map). The dot blot assay was used according to the manufacturers' instructions to detect the cytokine levels in serum samples collected from patients (Ray-Biotech). For each membrane, the individual background levels were subtracted. Individual densitometry analyses and averages for each group are shown [D: interleukin-1 alpha (IL-1 $\alpha$ ); E: tumour necrosis factor-alpha (TNF- $\alpha$ ); F: tumour growth factor-beta (TGF- $\beta$ ); G: IL-10; H: IL-8; I: monocyte chemoattractant protein (MCP)-2; J: regulated upon activation, normal T-cell expressed and secreted (RANTES); K: IL-13; L: IL-15]. Chronically HCV-infected patients were defined as patients with positive anti-HCV test results and detectable $\mathrm{HCV}$ genotype la viral RNA titres $(\mathrm{HCV}+)$ and patients who spontaneously cleared $\mathrm{HCV}$ presented positive anti-HCV test results and undetectable HCV RNA titres (HCV-). Differences with $\mathrm{p}<$ 0.05 were considered statistically significant $(*: \mathrm{p}<0.05 ; * * \mathrm{p}<0.001)$. DU: densitometry units (refer to the relative expression levels of detected cytokines); IFN- $\gamma$ : interferon-gamma; MIG: monokine-induced by IFN- $\gamma$; TNF- $\beta$ : tumour necrosis factor-beta. 
TABLE

Clinical and demographic characteristics of the patients

\begin{tabular}{|c|c|c|c|}
\hline Characteristics & $\begin{array}{l}\text { HCV+ } \\
(n=16)\end{array}$ & $\begin{array}{l}\text { HCV- } \\
(n=17)\end{array}$ & $\mathrm{p}$ \\
\hline Gender [female (\%)] & 68.75 & 76.4 & - \\
\hline Mean age (years $\pm \mathrm{SD})$ & $53.13 \pm 10.3$ & $49.12 \pm 12.83$ & 0.332 \\
\hline Mean ALT $(\mathrm{UI} / \mathrm{L} \pm \mathrm{SD})$ & $64.43 \pm 41.14$ & $29.8 \pm 15.07$ & 0.005 \\
\hline Mean AST (UI/L $\pm \mathrm{SD})$ & $61.86 \pm 42.45$ & $29.8 \pm 16.74$ & 0.012 \\
\hline Positive anti-HCV & 16 & 17 & - \\
\hline Viral genotype & 1a & Undetectable & - \\
\hline Mean viral titre $(\mathrm{UI} / \mathrm{L} \pm \mathrm{SD})$ & $1.064 \times 10^{\wedge} 7 \pm 1.56 \times 10^{\wedge} 7$ & Undetectable & - \\
\hline \multicolumn{4}{|l|}{ Lipid profile (mg/dL) } \\
\hline $\mathrm{COL}$ & $170.2 \pm 52.67$ & $177.3 \pm 59.42$ & 0.724 \\
\hline TG & $157.3 \pm 76.96$ & $148.6 \pm 63.4$ & 0.728 \\
\hline HDL & $38.27 \pm 9.74$ & $40.29 \pm 7.6$ & 0.514 \\
\hline LDL & $100.5 \pm 50.78$ & $119.9 \pm 34$ & 0.210 \\
\hline VLDL & $31.4 \pm 15.28$ & $30.29 \pm 13$ & 0.826 \\
\hline Body mass index $\left(\mathrm{kg} / \mathrm{m}^{2}\right)$ & $22.94 \pm 1.38$ & $22.9 \pm 1.26$ & 0.925 \\
\hline \multicolumn{4}{|l|}{ Grade of fibrosis (n) } \\
\hline $\mathrm{F} 1$ & 1 & - & - \\
\hline F1-F2 & 1 & - & - \\
\hline $\mathrm{F} 2$ & 1 & - & - \\
\hline F2-F3 & 2 & - & - \\
\hline F4 & 1 & - & - \\
\hline
\end{tabular}

ALT: alanine aminotransferase; AST: aspartate aminotransferase; COL: cholesterol; HCV-: patients who exhibited positive antihepatitis $\mathrm{C}$ virus test results and undetectable HCV RNA titres for more than six months. Averages of quantitative variables are expressed as mean \pm standard deviation (SD); HCV+: chronically HCV-infected patients who exhibited positive anti-HCV test results and detectable HCV genotype 1a viral RNA titres for more than six months; HDL: high density lipoprotein; LDL: low density lipoprotein; TG: triglyceride; VLDL: very low density lipoprotein.

$U$ test was used to calculate the statistical significance of the assay results. A $p$ value $\leq 0.05$ was considered statistically significant. Significant $\mathrm{p}$ values were corrected using the Bonferroni method to ensure that there were differences between the compared groups.

\section{RESULTS}

Based on HCV antibody and RNA viral profiles, patients were stratified into two groups: patients who spontaneously cleared $\mathrm{HCV}$ and patients with chronic $\mathrm{HCV}$ infection who continued to have detectable RNA titres. There were no significant gender or age differences found between the analysed groups. However, the patients with chronic HCV infection and detectable viral RNA presented significantly increased ALT and AST levels compared with the patients who had spontaneously cleared HCV. Genotype la was found in all of the chronically infected patients with detectable RNA. Fibrosis staging determined by elastography was conducted in a small number of participants (6) from the chronic HCV group. Patients with distinct stages of liver disease were included in the study and cirrhosis (F4) was found exclusively in one of these patients (Table).
In an attempt to rule out the influence of overweight and obesity on the clearance or evolution of chronic HCV infection, this study only included samples from patients with a normal body mass index. No differences in the lipid profiles of the analysed groups were found (Table). Representative dot blots showing the relative expression of cytokines in the study groups are shown in A, B in Figure. A low detection rate of certain cytokines, including IL-2, IL-6, IL-5, IFN- $\gamma$, IL-7, TNF- $\beta$, MCP-1 (CCL-2), MCP-3 (CCL-7), MIG (CCL-9), GRO- $\alpha$, GRO, IL-3, GMCSF and GCSF, was observed in our study groups (A-C in Figure). Interestingly, compared with chronic HCV-infected patients with detectable RNA, the patients who spontaneously cleared HCV displayed increased levels of IL- $1 \alpha$, TNF- $\alpha$, TGF- $\beta$, MCP-2 (CCL-8), IL-13 and IL-15 (D-F, I, K, L in Figure, respectively). In contrast, the chronic HCV-infected patients with detectable RNA showed increased levels of IL-8 and RANTES (CCL-5) compared with patients who spontaneously cleared $\mathrm{HCV}$ (H, J in Figure, respectively). No significant differences were found in IL-10 levels. However, there was a trend towards increased IL-10 levels in the chronic HCV-infected patients with detectable RNA ( $G$ in Figure). 
Viral and host factors are related to the progression of $\mathrm{HCV}$ infection. In 2009, it was demonstrated that $\mathrm{HCV}$ viral clearance is associated with genetic variation in the $I L-28 B$ gene (Ge et al. 2009, Thomas et al. 2009, Rauch et al. 2010). Numerous studies have been conducted on this family of cytokines and have led to several inconsistencies and controversies, including the possible correlation between serum protein levels and disease outcomes in chronic viral hepatitis patients (Torres et al. 2014). Thus, it is accepted that variations in the profile of cytokines involved in the immune response may contribute to the ability to clear HCV. These studies have mainly been conducted in regions where the virus is endemic (Shi et al. 2012), thus information on populations in regions of low endemicity is scarce. Herein, we characterised serum cytokine expression profiles in Mexican HCV-infected patients and found subtle differences in the cytokine profiles between distinct clinical courses of HCV infection. In our study, persistent infection with detectable genotype la viral content resulted in a proinflammatory profile characterised by increased levels of IL-8 and RANTES (CCL-5) and a trend towards increased IL-10 levels. These findings correlate with in vitro studies that have shown that natural killer cells from $\mathrm{HCV}$-infected patients are impaired in their capacity to activate dendritic cells due to the overproduction of IL-10 (Jinushi et al. 2004). Likewise, the increased levels of IL-8 found in the chronic HCV group in the present study may be related to the association between IL-8 production and IFN- $\alpha$ inhibition described in both in vivo and in vitro studies (Khabar et al. 1997, Jia et al. 2007). Moreover, the analysis of cytokines in each patient revealed a trend towards higher serum concentrations of IL-10 and IL-8 in patients with more severe liver damage (F2-F3 and F4) (data not shown). Altogether, our findings suggest that IL-10 and IL-8 overproduction may contribute to a lower probability of viral clearance, whereas homeostasis between pro-inflammatory [IL-1 $\alpha$, TNF- $\alpha$, MCP-2 (CCL-8)], anti-inflammatory (TGF- $\beta$ ), fibrogenic (IL-13) and immunoregulatory (IL15) profiles allows for viral clearance, as observed in patients with undetectable viral RNA levels. However, large-scale studies with adequate statistical power to support this hypothesis are needed. Furthermore, given that our data do not rule out the possibility that cytokine levels may be a consequence and not the cause of $\mathrm{HCV}$ clearance, future studies aimed at analysing the possibility of a reverse causation are necessary.

The progression of $\mathrm{HCV}$ infection is associated with the characteristics of lipid profiles in chronic HCV patients. In fact, it is accepted that lipid components associated with HCV infection are finely modulated in the Mexican population (Fierro et al. 2014). In the present study, no association between lipid profiles and viral clearance was found. Future studies that include overweight and obese individuals will allow the determination of the exact role of lipids in viral clearance.

We previously reported the influence of cytokines on the development of distinct clinical courses in children infected with hepatitis A (Fierro et al. 2012, Castro-Garcia et al. 2014) and on the development of occult hepatitis
$\mathrm{B}$ virus infection in native Mexican groups (Fierro et al. 2011). Herein, our findings suggest that cytokine expression can influence the extent of HCV development and provide important insights into cytokine-mediated mechanisms underlying the long-term persistence of HCV. In this context, efforts to determine whether biomarkers, including serum cytokines, can accurately predict the outcome of HCV infection are valuable for establishing better $\mathrm{HCV}$ control strategies in Latin American regions.

\section{ACKNOWLEDGEMENTS}

To Flor P Castro and Jesus Meza, for the technical assistance.

\section{REFERENCES}

Alvarado-Mora MV, Pinho JR 2013. Epidemiological update of hepatitis B, C and delta in Latin America. Antivir Ther 18: 429-433.

Castro-Garcia FP, Corral-Jara KF, Escobedo-Meléndez G, SandovalHernandez MA, Rosenstein Y, Roman S, Panduro A, Fierro NA 2014. Conjugated bilirubin adjusts cytokine profiles in hepatitis A virus infection by modulating function of signal transducer and activator of transcription factors. Immunology 143: 578-587.

EASL - European Association for Study of Liver 2014. EASL Clinical Practice Guidelines: management of hepatitis $\mathrm{C}$ virus infection. J Hepatol 60: 392-420.

Escobedo-Meléndez G, Fierro NA, Roman S, Maldonado-González M, Zepeda-Carrillo E, Panduro A 2012. Prevalence of hepatitis $\mathrm{A}, \mathrm{B}$ and $\mathrm{C}$ serological markers in children from western Mexico. Ann Hepatol 2: 194-201.

Fierro NA, Escobedo-Meléndez G, de Paz L, Realpe M, Roman S, Panduro A 2012. Cytokine expression profiles associated with distinct clinical courses in hepatitis A virus-infected children. Pediatr Infect Dis J 31: 870-871.

Fierro NA, Gonzalez-Aldaco K, Torres-Valadez R, Martinez-Lopez E, Roman S, Panduro A 2014. Immunologic, metabolic and genetic factors in hepatitis C virus infection. World J Gastroenterol 20: 3443-3456.

Fierro NA, Roman S, Realpe M, Hernandez-Nazara Z, Zepeda-Carrillo EA, Panduro A 2011. Multiple cytokine expression profiles reveal immune-based differences in occult hepatitis B genotype $\mathrm{H}$-infected Mexican Nahua patients. Mem Inst Oswaldo Cruz 106: 1007-1013.

Ge D, Fellay J, Thompson AJ, Simon JS, Shianna KV, Urban TJ, Heinzen EL, Qiu P, Bertelsen AH, Muir AJ, Sulkowski M, McHutchison JG, Goldstein DB 2009. Genetic variation in IL-28B predicts hepatitis C treatment-induced viral clearance. Nature 461: 399-401.

Hanafiah KM, Groeger J, Flaxman AD, Wiersma ST 2013. Global epidemiology of hepatitis $\mathrm{C}$ virus infection: new estimates of age-specific antibody to HCV seroprevalence. Hepatology 4: 1333-1342.

Jia Y, Wei L, Jiang D, Wang J, Cong X, Fei R 2007. Antiviral action of interferon-alpha against hepatitis $\mathrm{C}$ virus replicon and its modulation by interferon-gamma and interleukin-8. J Gastroenterol Hepatol 22: 1278-1285.

Jinushi M, Takehara T, Tatsumi T, Kanto T, Miyagi T, Suzuki T, Kanazawa Y, Hiramatsu N, Hayashi N 2004. Negative regulation of NK cell activities by inhibitory receptor CD94/NKG2A leads to altered NK cell-induced modulation of dendritic cell functions in chronic hepatitis C virus infection. J Immunol 173: 6072-6081.

Khabar KS, Al-Zoghaibi F, Al-Ahdal MN, Murayama T, Dhalla M, Mukaida N, Taha M, Al-Sedairy ST, Siddiqui Y, Kessie G, Matsushima K 1997. The alpha chemokine, interleukin 8, inhibits the antiviral action of interferon alpha. J Exp Med 1867: 1077-1085. 
Panduro A, Escobedo-Meléndez G, Fierro NA, Ruiz-Madrigal B, Zepeda-Carrillo EA, Román S 2011. Epidemiology of viral hepatitis in Mexico. Salud Publica Mexico 53: 37-45.

Rauch A, Kutalik Z, Descombes P, Cai T, Di Iulio J, Mueller T, Bochud M, Battegay M, Bernasconi E, Borovicka J, Colombo S, Cerny A, Dufour JF, Furrer H, Günthard HF, Heim M, Hirschel B, Malinverni R, Moradpour D, Müllhaupt B, Witteck A, Beckmann JS, Berg T, Bergmann S, Negro F, Telenti A, Bochud PY, Swiss Hepatitis C Cohort Study, Swiss HIV Cohort Study 2010. Genetic variation in IL28B is associated with chronic hepatitis C and treatment failure: a genome-wide association study. Gastroenterology 138: 1338-1345.

Rehermann B, Bertoletti A 2015. Immunological aspects of antiviral therapy of chronic hepatitis B virus and hepatitis $\mathrm{C}$ virus infections. Hepatology 61: 712-721.
Shi X, Pan Y, Wang M, Wang D, Li W, Jiang T, Zhang P, Chi X, Jiang Y, Gao Y, Zhong J, Sun B, Xu D, Jiang J, Niu J 2012. IL28B genetic variation is associated with spontaneous clearance of hepatitis $\mathrm{C}$ virus, treatment response, serum IL-28B levels in Chinese population. PLOS ONE 7: e37054.

Thomas DL, Thio CL, Martin MP, Qi Y, Ge D, O'Huigin C, Kidd J, Khakoo SI, Alexander G, Goedert JJ, Kirk GD, Donfield SM, Rosen HR, Tobler LH, Busch MP, McHutchison JG, Goldstein DB, Carrington M 2009. Genetic variation in IL28B and spontaneous clearance of hepatitis C virus. Nature 461: 798-801.

Torres C, Brahm J, Venegas M 2014. Lambda interferon serum levels in patients with chronic hepatitis $\mathrm{C}$ virus infection according to their response to therapy with pegylated interferon and ribavirin. J Interferon Cytokine Res 34: 106-110. 